\title{
Effective biofilm removal and changes in bacterial biofilm building capacity after wound debridement with low-frequency ultrasound as part of wound bed preparation before skin grafting
}

\author{
This article was published in the following Dove Press journal: \\ Chronic Wound Care Management and Research \\ 16 March 2017 \\ Number of times this article has been viewed
}

\section{Yuliya Yarets}

Clinical Laboratory Medicine Department, The Republican Scientific Centre for Radiation Medicine and Human Ecology, Gomel, Belarus

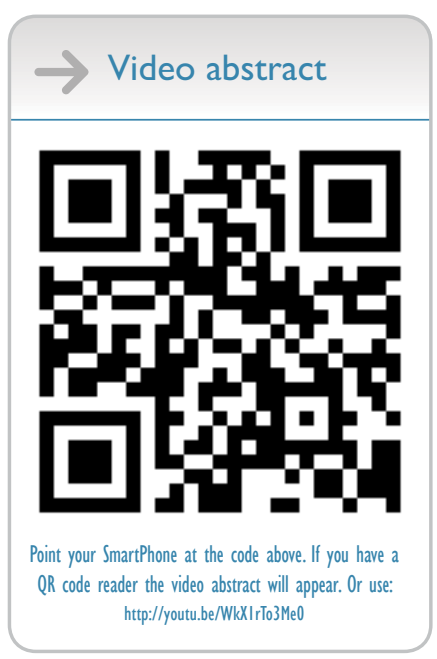

Correspondence: Yuliya Yarets Clinical Laboratory Medicine Department, The Republican Scientific Centre for Radiation Medicine and Human Ecology, 290 Illyich Street, Gomel 246040, Belarus

Tel +375293353472

Email artyut@mail.ru
Abstract: The aim of the study was to evaluate the efficacy of ultrasonic-assisted wound debridement (UAW) used for wound bed preparation of chronic wounds prior to skin grafting. Initially, 140 patients were enrolled into study. Group 1 patients $(n=53)$ with critically colonized wounds underwent a single UAW procedure before skin grafting. Group 2 patients ( $n=87$ ) with colonized wounds received two UAW sessions, skin grafting followed by the second UAW treatment. Initial wound classification in colonized and critically colonized wounds did not correlate with results from microbiological analysis of wound swab samples. Hence, comparison of efficacy of one or two debridement sessions was conducted solely for a similar group of patients, that is, patients with colonized wounds of group $1(n=40)$ and group $2(n=47)$. In wounds of group 1 patients, a single debridement session resulted in reduction of bacteria from $>10^{4}$ to $<10^{4} \mathrm{CFU} / \mathrm{mL}$. However, bacteria remaining at wound site showed minor differences in biofilm slime production, with skin graft failure being observed in $25 \%$ cases. In wounds of group 2 patients, two debridement sessions significantly reduced bacterial presence up to $<10^{2} \mathrm{CFU} / \mathrm{mL}$. Bacteria remaining at wound site showed low capacity for biofilm slime production and high accumulation of biomass; a complete graft healing was observed in all patients. We suggest two to three debridement sessions with UAW to be most effective in wound bed preparation before skin grafting of chronic wounds. UAW showed to be effective in cleaning the wound bed, destroying the extracellular substances in biofilms, and influencing biofilm slime building capacity of bacteria left at wound site.

Keywords: wound debridement, wound bed preparation, biofilm, low-frequency ultrasound, skin grafting, biofilm assay

\section{Introduction}

There are several factors influencing wound healing. Wounds of longer duration are associated with excessive inflammation, fibroblast senescence, and alterations in wound bed flora. ${ }^{1}$ All open wounds contain microorganisms from the patient's own flora or from exogenous sources. If microbes attach to the wound surface and proliferate, a biofilm will begin to develop. Increased microbial bioburden, defined as microbial load, presence of pathogenic organisms, and microbial diversity, has been proposed as an important predictor of poor healing outcomes. Peptide nucleic acid fluorescence in situ hybridization analyses on sections from chronic wounds have identified biofilm growing bacteria, which might explain why these wounds persist. ${ }^{2,3}$ Biofilms occur in 
$60 \%$ of all chronic and $6 \%$ of all acute wounds, thus impeding the healing pattern to follow in a sequential manner. ${ }^{4-5}$ When biofilms are suspected to be present, the physical removal of biofilms and suppression of biofilm reformation are a necessary part of wound bed preparation (WBP). ${ }^{6-8}$ Wound debridement can be considered an integral part of WBP not only to remove dead tissue, debris, and bacteria present in the wound bed but also to expose host defenses that are more intact and better suited to combat bacteria..$^{9,10}$ However, there is no evidence-based standardization in the debridement approach with questions remaining unanswered about the frequency of debridement and the extent of peripheral wound tissue removal necessary to promote healing that has been stated in the debridement positioning document of the European Wound Management Association. ${ }^{11}$ In clinical practice, it is at clinician's discretion to select the optimal debridement technique. ${ }^{12}$

Ultrasonic-assisted wound debridement (UAW) conducted with a low-frequency ultrasound device has been reported to have antibacterial effects and to promote healing by acoustic streaming with increased protein synthesis and production of growth factors. ${ }^{13}$ Results from a prospective, randomized controlled clinical trial showed UAW to be effective in debriding wounds without damaging the surrounding healthy tissue. ${ }^{14}$ Furthermore, current evidence has shown that UAW is effective in combating biofilms in vitro when used in combination with a polyhexamethylene biguanide hydrochloride-containing antiseptic. Due to direct disruption of biofilm extracellular matrix components (slime) and increased bacterial permeability, through a transient perturbation of the membrane, low-frequency ultrasound enhances the effect of antibiotics. ${ }^{15}$

Despite appropriate treatment, the presence of certain bacteria in nonhealing wounds can induce ulcer enlargement and delayed healing. ${ }^{16}$ In a recent retrospective study, the success rate of split-thickness skin grafting of chronic venous leg ulcers was correlated with the presence of Pseudomonas aeruginosa in these wounds. Results of this study suggest the hypothesis that $P$. aeruginosa presence in wounds, despite treatment, has a considerable impact on partial or rejection of split-thickness skin grafts. ${ }^{17}$

In a previously conducted pilot study with UAW used in combination with topical negative pressure, we demonstrated that there is a change in the dynamics of biofilm formation of Staphylococcus aureus following wound debridement with UAW, which was used for WBP before skin grafting. ${ }^{18}$ The aim of this study was to confirm these results in a practical setting involving patients treated at the Gomel Clinical City Hospital No. 1, Republic of Belarus.

\section{Patient population}

This prospective parallel case series study was conducted at the Gomel Clinical City Hospital No. 1, Republic of Belarus. In this study, a cohort of 140 patients was enrolled between 2010 and 2016. Patients were treated according to the local standard treatment protocol, which was applied within daily clinical practice. Treated wounds included traumatic ulcers as a result of mechanical or thermal trauma $(n=49)$, pressure sores $(n=14)$, venous leg ulcers $(n=32)$, and inflammatory ulcers, which derived from necrotizing infections of soft tissue or from surgical site infections $(n=45)$. From 140 patients enrolled, 86 were males and 54 females. Patient age ranged from 19 to 79 years. The duration of wounds was 28-365 days. Two of the patients had wounds that persisted for 5 and 17 years, respectively.

Before any patient was enrolled, an independent review board at Gomel State Medical University and Republican Centre for Radiation Medicine and Human Ecology approved the clinical study protocol. All the patients provided written informed consent at enrollment.

\section{Materials and methods Initial wound assessment}

The status of wounds was assessed by determining specific wound-related parameters, such as degree of damaged tissue with reference to the presence or absence of undermining and tunneling, wound bed appearance, amount of wound exudate, wound pain, and a detailed description of wound margins and the surrounding skin. ${ }^{19}$ Wound bioburden was evaluated according to the NERDS ( $\mathrm{N}$ - nonhealing wounds, $\mathrm{E}$ - exudate wounds, $\mathrm{R}$ - red and bleeding wound surface, $\mathrm{D}$ - debris [yellow or black necrotic tissue] on the wound surface, $\mathrm{S}$ - smell or unpleasant odor from the wound) and STONES ( $\mathrm{S}$ - size is bigger, $\mathrm{T}$ - temperature is increased, $\mathrm{O}-\mathrm{Os}$ probe to or exposed bone, $\mathrm{N}$ - new or satellite areas of breakdown, E - exudate, erythema, edema, S - smell) principle, which is based on easy-to-use clinical criteria used to diagnose superficial bacterial burden and deep tissue infection. ${ }^{20}$ Extensive swab sampling was conducted for semiquantitative and qualitative microbiological analysis. Furthermore, selected bacterial strains known to produce biofilms were isolated and further cultivation procedures helped determine their biofilm building capacity.

\section{Swab sampling and microbiological analysis}

Swab sampling and microbiological analysis were conducted at patients' admission after wound cleansing and after each 
UAW procedure applying the Levine technique. ${ }^{21}$ Before swabbing, wounds were cleaned with sterile saline solution or sterile water; gentle removal of excess debris applying moist saline gauze or if necessary conducting a superficial surgical debridement. After wound cleansing, a sterile culture swab was pressed and rotated over the area of the wound to bring wound fluid and bacteria to the surface. Swabbing of areas with slough and purulent discharge was avoided. A zigzag pattern was used for wounds larger than $5 \mathrm{~cm}^{2}$. Immediately after swabbing, samples were inoculated in prereduced media (Amies) and rapidly transported to the laboratory for further analysis. Clinical specimens were identified after plating and incubation according to standard procedures applied at the Departments of Medical Health Care in Belarus. ${ }^{22}$

The isolates were initially identified by standard microbiological techniques, including Gram staining and biochemical tests. Correct speciation of microorganisms was done using Vitek2 Compact automated system (Biomerieux, Marcy-l'Étoile, France) for Gram+ and Gram- strains. The total number of organisms presented in the wound was reported as $\log 10$ of the colony-forming units (CFU/ $\mathrm{mL}$ ). Microbiological examinations were carried out in the Laboratory of Cells Techniques of the Republican Centre for Radiation Medicine and Human Ecology (Gomel, Belarus).

\section{Determination of biofilm building capacity of isolated bacteria}

To detect the biofilm capacity of bacteria isolated from wounds, colonies of specific strains were used for the preparation of bacterial suspensions with bacterial density adjusted to $0.5 \mathrm{McFarland}$ standard $\left(\sim 10^{8}\right.$ cells $\left./ \mathrm{mL}\right)$. The methodology used for quantification of biofilm formation has been described elsewhere in detail and included the use of a microtiter plate modified in a way that a quantitative detection of bacterial adhesion and slime production of biofilm was measurable. ${ }^{18}$ Congo red and crystal violet stains were used to visualize both the matrix and the bacterial cells, and $95 \%$ ethanol was used to extract the stain connected to the biofilm. The optical density of each sample was measured at a wavelength of $540 \mathrm{~nm}$ (for crystal violet/ethanol solution) and $490 \mathrm{~nm}$ (for Congo red/ethanol solution) using a Sirio microplate reader (Seac \& Radium Group, Calenzano, Italy).

Biofilm-forming bacterial strains derived from patients' swab samples and biofilm-forming capacity of selected strains was observed before and after UAW.

\section{UAW treatment modalities for WBP}

WBP included one or two wound debridement sessions with a $25 \mathrm{kHz}$ low-frequency UAW debridement device, SONOCA $185^{\circledR}$ (Söring GmbH, Quickborn, Germany). Each UAW procedure was conducted under general or local anesthesia. The UAW device was applied for 5-15 seconds per probe head area $(1 \times 1 \mathrm{~cm})$ onto the edges and the surfaces of all wounds. Isotonic normal saline was used as a coupling/irrigation medium between the handheld probe and the wound. Depending on the treatment protocol and frequency of UAW sessions, patients were divided in two groups, namely group 1 and group 2 (Figure 1).

The effectiveness of UAW in cleaning the wound, removing biofilms, and preparing the wound bed for further skin

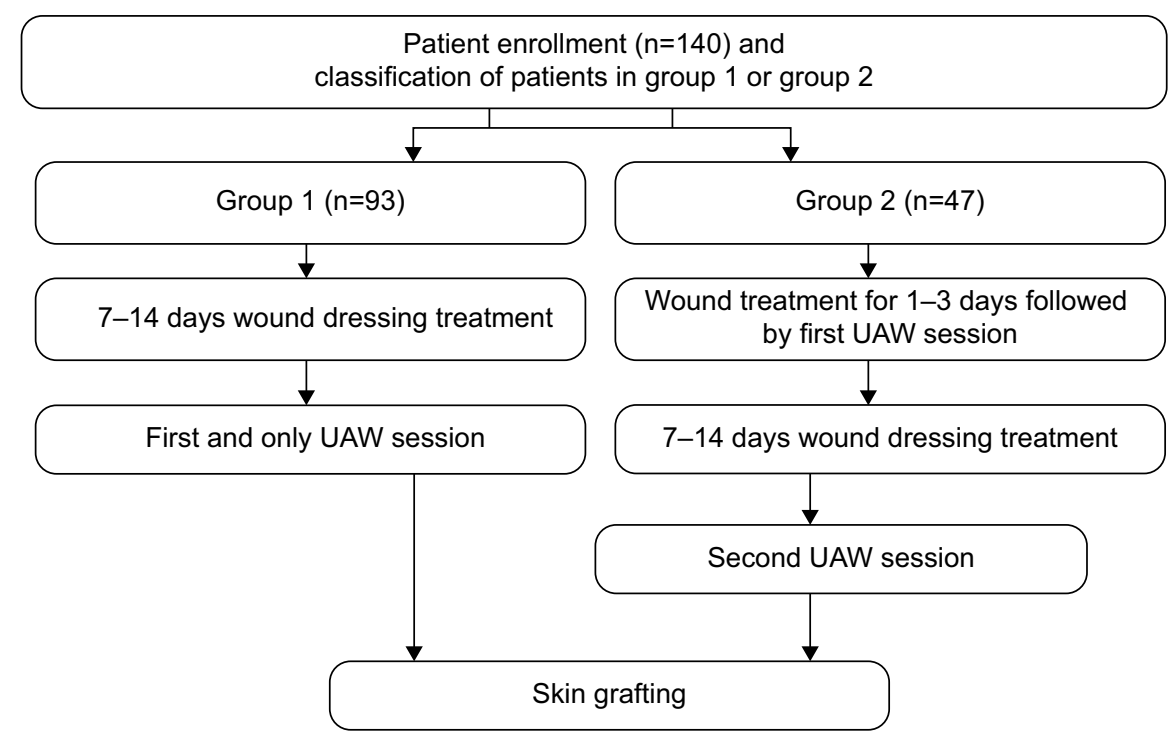

Figure I Initial wound evaluation and treatment modalities.

Abbreviation: UAW, ultrasonic-assisted wound debridement. 
grafting was evaluated on the basis of the clinical picture of wounds, including a detailed analysis of microbial load and diversity. Treatment outcome in both groups of patients was evaluated determining the take-rate and healing of grafted wounds.

\section{Treatment protocol for patients in group I}

Group 1 included 93 patients in total. After initial wound cleansing with saline solution, patients received 7-14 days of wound therapy following the local treatment protocol of the Gomel Clinical City Hospital No 1, Republic of Belarus. Treatment measures included the use of antiseptic bandages, chlorhexidine, povidone iodine, and polyethylene glycolbased ointments. Following initial wound therapy, patients underwent one UAW session as WBP measure before surgical wound closure and skin grafting.

\section{Treatment protocol for patients in group 2}

Group 2 included 47 patients in total. After patient's admission, all wounds were cleaned with saline solution and then treated for 1-3 days according to the local treatment protocol of the Gomel Clinical City Hospital No 1, Republic of Belarus. Then the first UAW procedure was conducted followed by local wound treatment for 7-14 days according to the local treatment protocol of the Gomel Clinical City Hospital No 1, Republic of Belarus. After 7-14 days of dressing treatment, the second UAW procedure was conducted shortly before surgical wound closure with skin grafting.

\section{Readiness for skin grafting}

The clinical picture of debrided wounds was used for evaluating readiness of wounds for further skin grafting. Clinical signs, such as the absence of inflammation, wound adhesiveness, mature red or bright pink granulation, and the presence of edged epithelialization, were taken under consideration. ${ }^{23}$ Furthermore, swab sampling was conducted to determine the bacteriological status of wounds shortly before skin grafting.

\section{Skin grafting outcome}

Skin grafting outcome was evaluated on the basis of clinical signs of fixation, including the color and degree of fixation of the graft, and the degree of exudation after surgical wound closure. Skin grafting procedure was defined as being successful when graft fixation occurred on the third or fourth day after surgery and complete graft healing occurred within
7-9 days after surgery. The presence of graft instability was evaluated based on paleness and rejection or dissolution of the graft $8 \pm 3$ days after skin grafting. If a graft failed, the procedure of skin grafting was repeated.

\section{Statistics}

The frequency of each nominal or ranked clinical and laboratory parameter of treated chronic wounds was expressed as percentage. Nonparametric Mann-Whitney $U$-test was used to compare biofilm-forming capacity of bacterial strains before and after UAW treatment and the Wilcoxon test was used to compare dependent samples (variables). Results were considered to be statistically significant when $p$ value is $<0.05$.

Cluster analysis of data was done using the statistical program StatSoft. A horizontal Hierarchical Tree Plot was prepared to determine the correlation of results derived from microbiological swab sampling analysis with the results obtained from clinical wound assessment.

\section{Results}

\section{Initial clinical evaluation of wounds based on NERDS and STONES criteria}

Results of initial clinical wound assessment are summarized in Table 1. Wounds of all 140 treated patients were contaminated with bacteria showing signs of local inflammation. Granulation tissue was detected in all wounds; however, its

Table I Initial clinical evaluation of wounds $(n=\mid 40)$

\begin{tabular}{|c|c|}
\hline Parameter & $\begin{array}{l}\text { Wounds, } \\
\%(n=140)\end{array}$ \\
\hline \multicolumn{2}{|l|}{ Granulation tissue } \\
\hline Discolored type of tissue (bright red) dull and friable & $38(53 / 140)$ \\
\hline $\begin{array}{l}\text { Pale granulation with signs of atrophy and scarring } \\
\text { or red friable hypergranulation }\end{array}$ & $62(87 / / 40)$ \\
\hline \multicolumn{2}{|l|}{$\begin{array}{l}\text { or red triable hypergranulation } \\
\text { Exudate levels }\end{array}$} \\
\hline High & $0(0 / 140)$ \\
\hline Moderate & $54(75 / 140)$ \\
\hline Low or absent & $46(65 / 140)$ \\
\hline \multicolumn{2}{|l|}{ Exudate character } \\
\hline Serous or serous-fibrinous & $84(118 / 140)$ \\
\hline Purulent & $16(22 / 140)$ \\
\hline \multicolumn{2}{|l|}{ Malodor } \\
\hline Absent & $30(42 / 140)$ \\
\hline Present & $70(98 / 140)$ \\
\hline \multicolumn{2}{|l|}{ Pain } \\
\hline Absent & $40(56 / 140)$ \\
\hline Present & $60(84 / 140)$ \\
\hline \multicolumn{2}{|l|}{ Wound margin skin } \\
\hline Skin erythema & $30(38 / 140)$ \\
\hline Swelling-edema or induration of peripheral tissue & $90(126 / 140)$ \\
\hline Local temperature increasing & $20(25 / 140)$ \\
\hline
\end{tabular}


quantity and quality varied considerably with none of the wounds showing moist and firm granulation with healthy appearance. In 38\% (53/140) of wounds, granulation showed a discolored type of tissue (bright red) dull and friable, and in $62 \%(87 / 140)$ of wounds, the tissue was pale, with signs of atrophy and scarring or red friable hypergranulation. Also, slough, necrotic tissue, and spots of epithelial tissue were detected in most wounds.

Wound exudate levels were low in 46\% (65/140) and moderate in $54 \%(75 / 140)$ of cases. The types of wound exudates were mainly serous and fibrinous or a combination of both (84\%). Wound exudates showing (bright red) dull and friable granulation tissue 38\% (53/140) showed a purulent consistency. Malodor was detected in 70\% (98/140) of wounds.

In $90 \%$ (126/140) of cases, wound margins showed abnormalities, such as swelling or edema. Peripheral tissue-skin erythema was detected in $30 \%(38 / 140)$ and increase in local temperature was measured in $20 \%(25 / 140)$ cases.

From all treated patients, $60 \%(84 / 140)$ complained about wound pain.

\section{Results of wound swab analysis at baseline}

A first bacteriological evaluation of initial swab samples of all 140 patients showed monomicrobial presence in 56 (40\%) cases and polymicrobial presence in 84 (60\%) cases. From 200 bacterial strains being detected, Staphylococcus spp. corresponded to 90 isolates, $S$. aureus to 72 isolates, nonfermenting Gram- rods (NFR) Pseudomonas, Acinetobacter spp. to 42 isolates, Enterobacteriaceae spp., Proteus mirabilis, Escherichia coli, Enterobacter cloacae, Klebsiella pneumoniae to 28 strains, and Enterococcus faecalis to 40 isolates (Figure 2).

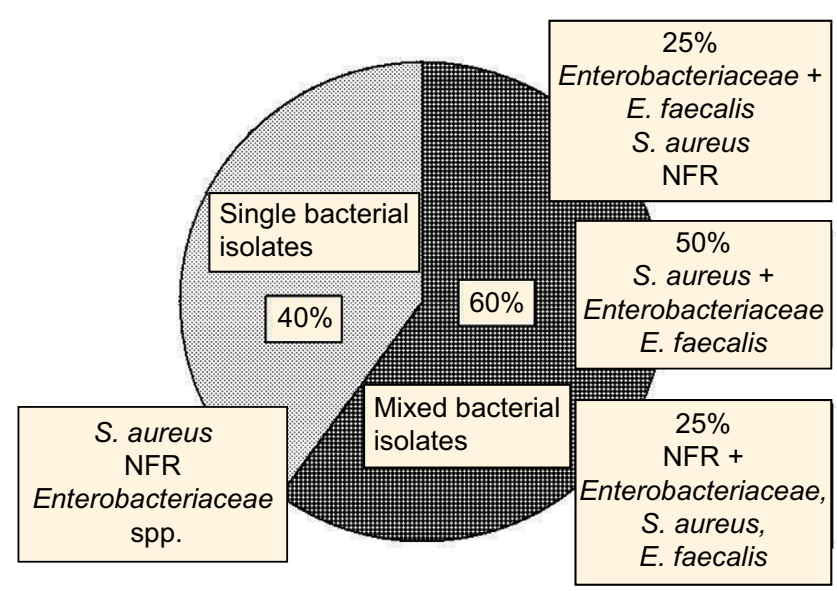

Figure 2 Results of wound swab analysis at baseline.

Abbreviations: NFR, nonfermenting Gram-rods; S. aureus, Staphylococcus aureus; E. faecalis, Enterococcus faecalis.
Further microbiological analysis of swab samples confirmed $>50 \%(n=100)$ of isolated strains showed a bacterial presence of $10^{6}-10^{8} \mathrm{CFU} / \mathrm{mL}$. In $34 \%(n=68)$ of swab samples, bacteria were isolated only after the additional cultivation of the swab samples in broth media and the bacterial count was $10^{1}-10^{2} \mathrm{CFU} / \mathrm{mL}$. In $10 \%$ of wounds, the number of bacteria was $10^{5} \mathrm{CFU} / \mathrm{mL}$, and in $6 \%$ of wounds, the number of bacteria was $10^{3}-10^{4} \mathrm{CFU} / \mathrm{mL}$.

Furthermore, $50 \%(n=100)$ of isolated strains from chronic wounds showed a bacterial presence of $10^{6}-10^{8}$ $\mathrm{CFU} / \mathrm{mL}$. In $34 \%(\mathrm{n}=68)$ of cases, bacteria were isolated only after the additional cultivation of the wounds samples in broth media (the bacterial count was $10^{1}-10^{2} \mathrm{CFU} / \mathrm{mL}$ ). In $10 \%$ and $6 \%$ of wounds, the number of bacteria was $10^{5}$ and $10^{3}-10^{4} \mathrm{CFU} / \mathrm{mL}$ (Figure 3).

\section{Biofilm building capacity of bacterial isolates at baseline}

Initially, it was found that $60 \%$ of Gram+ isolates $(n=78)$ and $50 \%$ of Gram- isolates $(n=35)$ were associated with a strong biofilm slime production. Of the 200 clinical isolates, $24(12 \%)$ were designated as non-slime producers and $36(18 \%)$ as weak slime producers. About $19 \%$ of Gram+ strains and $28 \%$ of Gram- strains were considered moderate biofilm builders. As for the biomass accumulation, the isolates showed a diverse behavior in comparison with slimeproducing isolates. A strong ability to increase the number of microbial cells was revealed less frequently ( $22 \%$ for Gram+ and $20 \%$ for Gram- strains) than a strong slime-producing ability $\left(\chi^{2}=36 ; \chi^{2}=14, p<0.01\right.$ for Gram + and Gram- strains, respectively). The same results were found for those bacterial strains showing a weak biofilm-forming ability $\left(\chi^{2}=44\right.$ and $\chi^{2}=45, p<0.01$ for Gram + and Gram - strains, respectively).

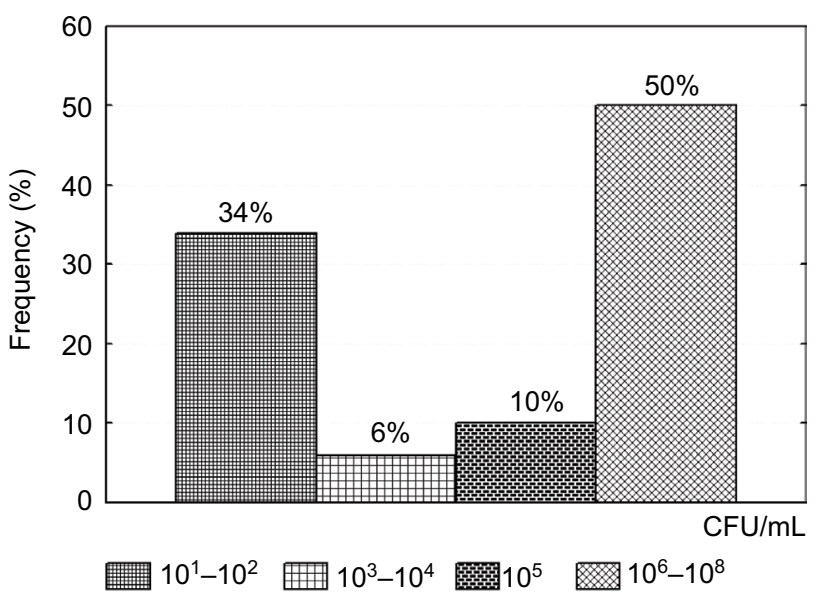

Figure 3 Initial distribution of bacterial presence in $\mathrm{CFU} / \mathrm{mL}$ isolates. Abbreviation: $\mathrm{CFU}$, colony forming units. 
The data showed good negative correlation between the biomass accumulation and slime production for biofilmforming Gram+ isolates from chronic wounds of patients with $r_{s}=-0.7, p<0.01$. The power of the same association for Gram- biofilm-forming isolates was weaker with $r_{s}=-0.4$, $p=0.01$ (Table 2).

\section{Cluster analysis and correlation of the clinical picture with swab sampling results}

Results derived from clinical evaluation of wound appearance according to NERDS and STONES criteria were correlated with the results of wound swab sampling analysis, for example, presence of Gram+ and Gram- strains,

Table 2 Biofilm-forming ability of 200 bacterial isolates at baseline

\begin{tabular}{|c|c|c|c|c|c|c|c|c|}
\hline \multirow[t]{3}{*}{ Organism } & \multicolumn{8}{|c|}{$\begin{array}{l}\text { Bacterial strains showing ability to } \\
\text { form biofilms, \% }\end{array}$} \\
\hline & \multicolumn{2}{|c|}{ Non } & \multicolumn{2}{|c|}{ Weak } & \multicolumn{2}{|c|}{ Moderate } & \multicolumn{2}{|c|}{ Strong } \\
\hline & B & $\mathbf{S}$ & B & $\mathbf{S}$ & B & $\mathbf{S}$ & B & $\mathbf{S}$ \\
\hline $\begin{array}{l}\text { Gram+ isolates } \\
\text { Staphylococcus spp. } \\
\text { Enterococcus faecalis }\end{array}$ & 7 & 12 & 44 & $8^{a}$ & 27 & 19 & 22 & $60^{a}$ \\
\hline $\begin{array}{l}\text { Gram- isolates } \\
\text { Nonfermenting } \\
\text { Gram- rods } \\
\text { Enterobacteriaceae }\end{array}$ & 10 & 12 & 70 & $10^{\mathrm{a}}$ & 10 & 28 & 20 & $50^{\mathrm{a}}$ \\
\hline
\end{tabular}

Notes: Good negative correlation $\left(r_{s}=-0.7, p<0.01\right)$ between the biomass accumulation and slime production for biofilm-forming Gram+ isolates from chronic wounds of patients. The power of the same association for Gram- biofilm-forming isolates was weaker: $r_{s}=-0.4, p=0.01$. ${ }^{a}$ The differences between the frequency of $B$ and $S$.

Abbreviations: $\mathrm{B}$, biomass accumulation; $\mathrm{S}$, slime production.
$\mathrm{CFU} / \mathrm{mL}$, biomass accumulation, and slime production of biofilm-forming species. Collected data were used for reclassification of all wounds in a hierarchical agglomerative clustering with k-means algorithm used to classify wounds types of patients in clusters according to the results of correlation, namely, Cluster 1 with critically colonized wounds or wounds with local infection and Cluster 2 with colonized wounds (Figure 4).

Cluster 1 wounds included those wounds showing a combined type of wound bed including presence of necrotic tissue, such as eschar or slough; showing no epithelialization, with moderate purulent exudate; and presence of surrounding skin abnormalities, such as erythema and local temperature increase. Cluster 1 wounds were also characterized with discolored (bright red) dull and friable granulation tissue. Microbiological analysis of swab samples showed these wounds to be mono- or polymicrobial with weak or absent biofilm slime production, but with a strong or moderate biomass accumulation. These wounds were classified critically colonized with a superficial or local wound infection.

Cluster 2 wounds showed a combined type of wound bed with signs of epithelialization, low level of serous or serousfibrinous exudates and absence of erythema, and local temperature increase in the surrounding skin. Granulation tissue of wounds in Cluster 2 showed to be pale with signs of atrophy and scarring or with hypergranulation. Microbiological analysis of wound swab samples 2 showed the presence of bacteria with strong or moderate slime production and a

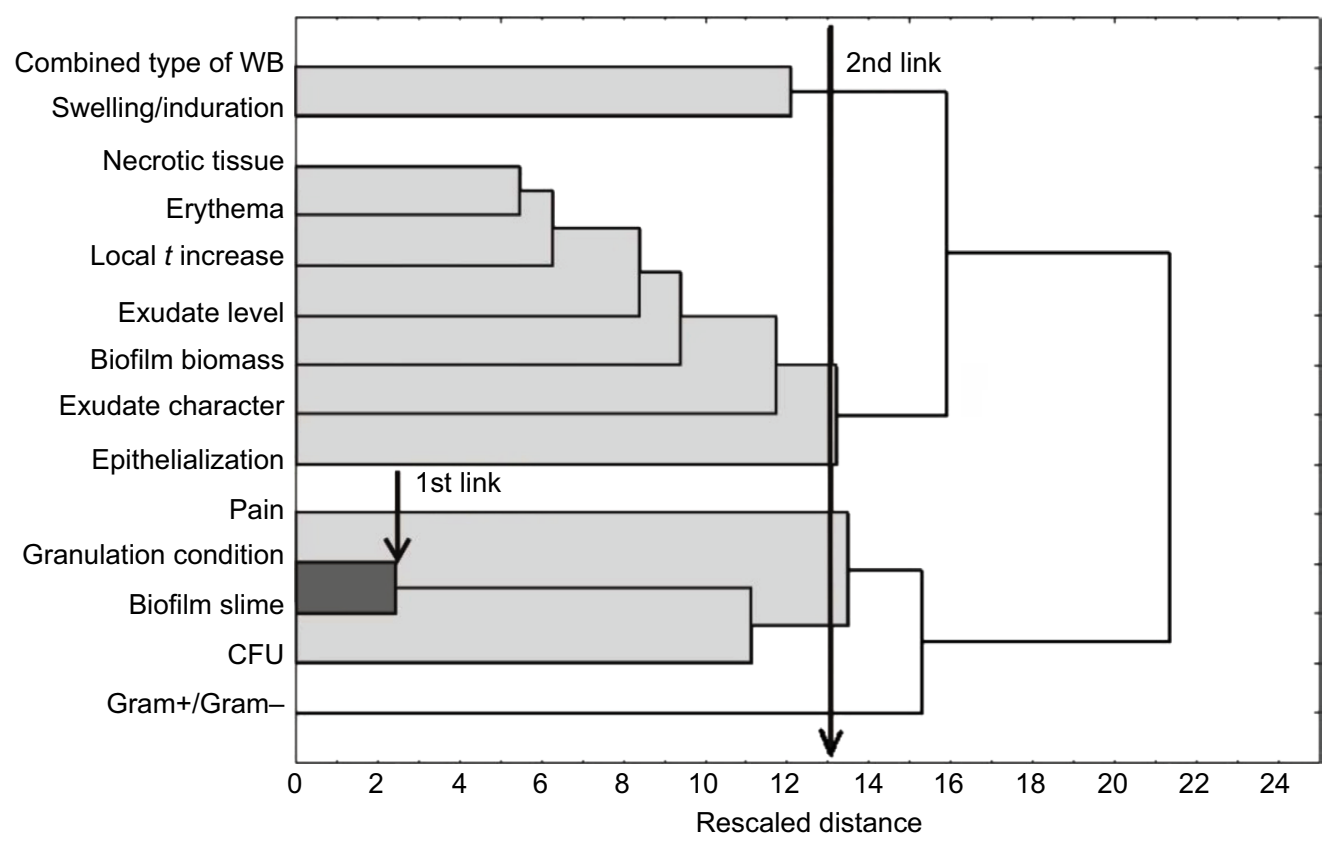

Figure 4 k-means clustering of clinical wound assessment and swab sampling analysis.

Notes: Cluster I=critically colonized or local infected wounds, Cluster $2=$ colonized wounds

Abbreviations: CFU, colony-forming units; WB, wound bed. 
weak level of biomass accumulation. These wounds were classified as colonized wounds. The presence or absence of wound pain did not influence classification or wounds in cluster types.

From all 140 treated patients, 53 wounds in the control group (group 1) showed to be critically colonized with a local wound infection and 40 colonized wounds. In the treatment group (group 2), all 47 wounds of patients were confirmed to be colonized.

\section{Treatment results}

Initial conservative wound treatment in group 1 patients with colonized wounds $(n=40)$ provided the initiation of the process of necrotic tissue removal and resulted in decrease of initial microbial bioburden from $>10^{4}$ to $<10^{4} \mathrm{CFU} / \mathrm{mL}$. The clinical picture improved as a consequence of wound dressing treatment, but the significant changes and the definitive clearance of slough, necrotic, fibrous, and unhealthy tissues were the result of a single debridement session with UAW $\left(\chi^{2}\right.$ trend for different parameters was $25-38, p<0.001)$. Unhealthy tissue removal resulted in statistically significant bacterial reduction $\left(\chi^{2}\right.$ for trend $\left.=22.4, p<0.01\right)$, thus providing the conditions for fixation of skin grafts. The tendency $(p>0.05)$ of wound margins abnormalities (skin erythema, peripheral tissue swelling/edema or induration, and local temperature increased) disappeared as a consequence of UAW. All wounds showed active re-epithelialization. Exudate production diminished as well as purulent character of exudates.

Swab sampling of group 1 patients with colonized wounds resulted in $>10^{4} \mathrm{CFU} / \mathrm{mL}$ at patient's admission. After wound dressing treatment for 7-14 days followed by a single UAW session before skin grafting, the bacterial level was reduced to $<10^{4} \mathrm{CFU} / \mathrm{mL}$. However, despite reduction in bacteria, only minor differences in biofilm slime production of isolated bacteria were detected when compared with initial values at patient's admission (Figure 5).

In group 2 patients with colonized wounds $(n=47)$, the most expressed changes in the clinical picture and microbiological condition of wounds were observed right after the second debridement procedure with UAW. Results from swab sampling showed that bacteria could still be detected but in a less degree with $10^{1}-10^{2} \mathrm{CFU} / \mathrm{mL}\left(\chi^{2}\right.$ for trend $=28.5$, $p<0.01)$. In $40 \%$ of cases $(\mathrm{n}=19)$ bacteria were not isolated from wounds even after the additional cultivation. Predominantly $90 \%$ of bacterial strains were characterized as species with low capacity for biofilm slime production (Chi-square for trend=35.6; $P<0.001$ ). A significant reduction of strong and moderate biofilm producing bacteria was also detected (Chi-square for trend=24.2; $P<0.01$ ) (Figure 6).

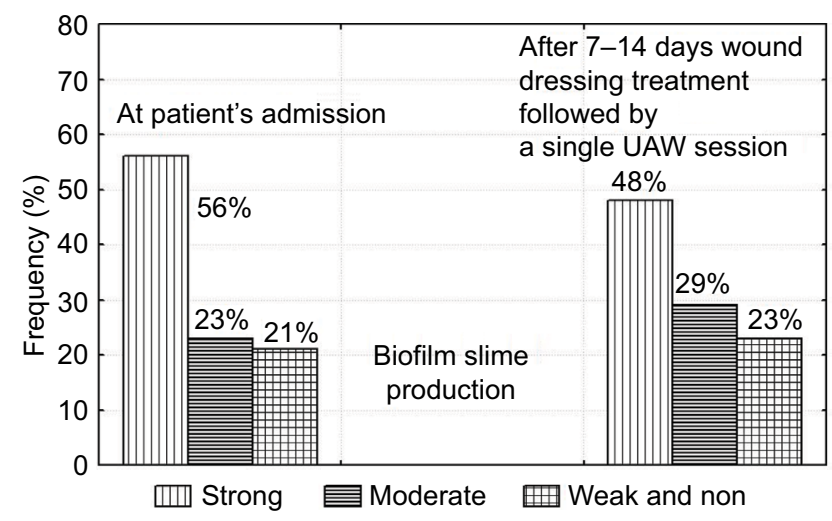

Figure 5 Biofilm slime production of isolated bacteria present at wounds site of colonized wounds of group I patients $(n=40)$.

Notes: Left group of bars represents results at patient's admission and right side results after 7-14 days treatment with wound dressings followed by a single UAW session before skin grafting.

Abbreviation: UAW ultrasonic-assisted wound debridement.

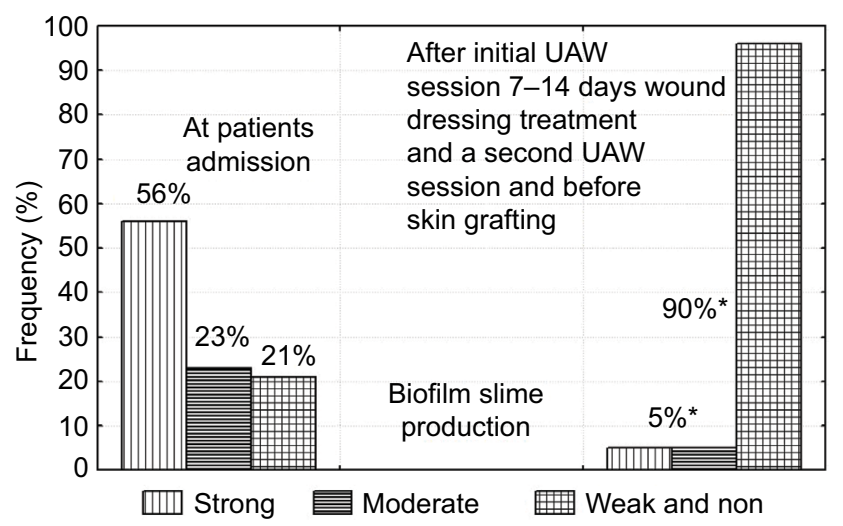

Figure 6 Biofilm slime production of bacteria present at wounds site of colonized wounds of group 2 patients ( $n=47$ ).

Notes: Left group of bars represents results at patient's admission and right side results after the second UAW session before skin grafting. *Statistically significant differences were obtained using the chi-square test for trend.

Abbreviation: UAW ultrasonic-assisted wound debridement.

\section{Skin grafting results}

At the moment of surgical closure, all wounds were characterized with a satisfactory granulation condition, absence of necrotic and nonviable tissue, reduction or disappearance of wound margins abnormalities, and re-epithelialization initiation.

Despite $<10^{4} \mathrm{CFU} / \mathrm{mL}$ bacteria detected at wound site shortly before grafting wounds of group 1 patients, complete graft healing was observed in $75 \%$ of cases (30/40) and complications within the immediate postprocedural period in $25 \%$ cases (10/40). In wounds of group 2 patients with $10^{1}-10^{2}$ $\mathrm{CFU} / \mathrm{mL}$ bacteria detected at wound site shortly before skin grafting, complete graft take was observed within 1-3 days and complete graft healing after 7-9 days with no complications being observed in all 47 patients. 


\section{Discussion}

Venous ulcers, diabetic ulcers, and pressure ulcers are classified as chronic wounds with specific characteristics, such as a prolonged inflammatory phase, persistent infections, formation of microbial biofilms, and ineffective dermal/ epidermal cell response. ${ }^{24}$ Experience derived from daily clinical practice of wound therapy has shown that removal of necrotic or devitalized tissue is perhaps the most important part of local wound treatment and minimizes the bioburden of wounds by decreasing the presence of bacteria, reducing the hypoxic part of the wound, and diminishing the local inflammatory reaction. ${ }^{17}$

Extensive and detailed wound assessment at patient's admission is a prerequisite for determining appropriate treatment pathway to be followed. However, wound bioburden and classification of wounds in colonized or locally infected wounds are not an easy task. Discrepancies between microbial population sizes and clinical indicators for the infection of chronic wounds have been reported with experts claiming for a stricter definition of the terms "problematic bacterial load" or "critical colonization" before these can be used in clinical practice or as endpoints in research. ${ }^{25}$ In this study, initial clinical wound assessment according to NERDS and STONES resulted in classification of all 140 wounds as colonized wounds. Patients were split in two groups assuming the only difference between the groups were treatment modalities, for example, the amount of UAW sessions conducted as part of treatment protocol. However, initial wound classification did not correlate with the results obtained from microbiological analysis with only 40 wounds from group 1 ( $\mathrm{n}=93$ ) confirming to be colonized and 53 wounds resulting critically colonized wounds with a local wound infection. In group 2 patients, all 47 wounds confirmed to be colonized. As a result, we decided to compare only results of 40 colonized wounds from group 1 patients, with the results of 47 colonized wounds from group 2 patients to determine the influence of one or two UAW sessions on skin grafting outcome and healing.

In this study, results of initial swab sampling analysis showed $60 \%$ polymicrobial and $40 \%$ monomicrobial presence in wounds at patient's admission. Polymicrobial biofilm presence has been reported to impair all wound healing when compared with the monospecies infection. ${ }^{26} \mathrm{We}$ can confirm dressing treatment followed by one UAW session resulted in effective wound cleansing and biofilm removal of all wounds of group 1 patients. Furthermore, swab sampling analysis showed a satisfactory clinical appearance and reduced bacteria presence with $<10^{4} \mathrm{CFU} / \mathrm{mL}$. However, despite effective wound cleansing and biofilm removal, a single UAW session seemed to reduce bacteria presence in wounds but cause only minor differences in biofilm slime production of isolated bacteria.

Given the polymicrobial nature of treated wounds, it is important to gain an understanding of the development of mixed species biofilms and the ways in which they affect healing. In this study, remaining bacteria confirmed to be moderate-to-strong biofilm slime builder species. As a result, complications were observed in $25 \%$ of cases (10/40) within the immediate postprocedural period of skin grafting in group 1 wounds. These results confirm reports from others; in that, even in case of extensive surgical debridement in combination with split skin transplant, the presence of $P$. aeruginosa prior to surgery seems to influence the healing. ${ }^{17}$ Reports in the literature have shown that the composition of biofilms, their physicochemical properties, microbial numbers, and the host's pathophysiology influence the sustainability of a pathogenic biofilm in a wound and its resistance to interventions. ${ }^{27}$ The results of skin grafting in group 1 wounds can be explained by the presence of bacterial strains with a high or moderate potential to quickly form biofilms, which may affect the contact characteristics of the wound bed and impede the process of graft fixation, resulting in graft rejection.

In a recently published proof of principle pilot study with noncontact low-frequency ultrasound used for the treatment of diabetic foot ulcers, it was suggested three times a week application to be most effective in inhibiting proinflammatory cytokines and significantly improving tissue regeneration. ${ }^{28}$ We can confirm these observations looking at the results of group 2 patients, with initial UAW treatment session followed by dressing treatment and a second UAW session resulting in effective wound cleansing and biofilm removal. Wounds of group 2 patients showed a satisfactory clinical appearance with significantly reduced bacterial presence up to $<10^{2} \mathrm{CFU} / \mathrm{mL}$ shortly before skin grafting. Furthermore, there is a tendency in UAW to influence biofilm building capacity, for example, slime building in bacteria left at wound site showing low capacity for biofilm slime production and high accumulation of biofilm biomass. As a result of treatment of all 47 wounds in group 2 patients, a complete graft healing with no complications was observed.

\section{Conclusion}

Results of this study confirm the initial findings of a previously conducted pilot study showing that UAW as part of the treatment protocol of the Gomel Clinical City Hospital No 1, Republic of Belarus, is most effective in cleaning the 
wound bed, removing bioburden, and disrupting biofilms. We suggest therapeutic application of UAW two or three times to be most effective in WBP and before skin grafting of chronic wounds. UAW resulted effective in destroying the extracellular polymeric substances in biofilms, and there is a tendency in UAW to influence biofilm building capacity, for example, slime building in bacteria left at wound site.

\section{Study limitations}

Limitations of this study include small sample size and enrollment of an in-homogenous group of patients. Despite detailed clinical wound evaluation including swab sampling at patient admission, the results of swab sampling analysis showed discrepancies between initial classification of wounds based on the clinical picture with the results of wound sampling analysis. However, these limitations are a result of our main study objective, which was to conduct a study under "real-life daily clinical practice conditions".

\section{Acknowledgment}

The author thanks Cecilia Welling, Germany, for her support in preparing this manuscript and Natallia Shevchenko, $\mathrm{PhD}$, The Head of the Department of Cell Technique for outstanding technical assistance.

\section{Disclosure}

The author reports no conflicts of interest in this work.

\section{References}

1. Bosanquet DC, Harding KG. Wound duration and healing rates: Cause or effect? Wound Repair Regen. 2014;22(2):143-150.

2. Fazli M, Bjarnsholt T, Kirketerp-Moller K, et al. Nonrandom distribution of Pseudomonas aeruginosa and Staphylococcus aureus in chronic wounds J Clin Microbiol. 2009; 47(12):4084-4089.

3. Bjarnsholt T, Kirketerp-Møller K, Jensen PØ, et al. Why chronic wounds will not heal: a novel hypothesis Wound Repair Regen. 2008;16(1):2-10.

4. James GA, Swogger E, Wolcott R, et al. Biofilms in chronic wounds. Wound Repair Regen. 2008;16(1):37-44.

5. Wu S, Skratsky M. Debridement and the current state of play. Podiatry Management. 2012;145-151.

6. Sibbald G, Orsted H, Coutts P, Keast D. Best practice guidelines for the preparing the wound bed: update 2006. Adv Skin Wound Care. 2006; 20(7):390-405.

7. Schultz GS, Sibbald RG, Falanga V, et al. Wound bed preparation: a systemic approach to wound management. Wound Repair Regen. 2013; 11(Suppl 1):S1-S28.

8. Kirshen C, Woo K, Ayello EA, Sibbald RG. Debridement: a vital component of wound bed preparation. Adv Skin Wound Care. 2006;19(9):506-517.
9. Cardinal M, Eisenbud D, Armstrong D, et al. Serial surgical debridement: a retrospective study on clinical outcomes in chronic lower extremity wounds. Wound Repair Regen. 2009;17(3):306-311.

10. Piaggesi A, Schipani E, Campi F, et al. Conservative surgical approach versus non-surgical management for diabetic neuropathic foot ulcers: a randomized trial. Diabet Med. 1998;15(5):412-417.

11. Strohal R, Apelqvist J, Dissemond J. et al. EWMA Document: Debridement. J Wound Care. 2013;22(Suppl 1):S1-S52.

12. Madhok BM, Vowden K, Vowden P. New techniques for wound debridemement. Int Wound J. 2013;10(3):247-251.

13. Stanisic MM, Provo BR, Larson DL, Kloth LC. Wound debridement with $25 \mathrm{KHz}$ ultrasound. Adv Skin Wound Care. 2005;18(9): 484-490.

14. Herberger K, Franzke N, Blome C, Kirsten N, Augustin M. Efficacy, tolerability and patient benefit of ultrasound- assisted wound treatment versus surgical treatment: a randomized clinical study. Dermatology. 2011; 222(3):244-249.

15. Geisler Crone S, Garde C, Bjansholt T, Alhede M. A novel in vitro wound biofilm model to evaluate antibiofilm strategies such as lowfrequency ultrasonic assisted wound debridement (UAW). J Wound Care. 2015;24(2):64-72.

16. Kirketerp-Møller K, Jensen PØ, Fazli M, et al. Distribution, organization, and ecology of bacteria in chronic wounds. J Clin Microbiol. 2008;46(8):2717-2722.

17. Høgsberg T, Bjarnsholt T, Thomsen JS, Kirketerp-Møller K. Success rate of split-thickness skin grafting of chronic venous leg ulcers depends on the presence of Pseudomonas aeruginosa: a retrospective study. PLoS One. 2011;6(5):e20492.

18. Yarets Y. The biofilm-forming capacity of Staphylococcus aureus from chronic wounds can be useful for determining wound bed preparation methods. EWMA Journal. 2013;13(1):7-18.

19. Keast DH, Bowering KC, Evans Wayne A, Mackean GL, Burrows C, D'Souza L. MEASURE: a proposed assessment framework for developing best practice recommendations for wound assessment. Wound Repair Regen. 2004;12(Suppl S1):1-17.

20. Sibbald GR, Woo K, Ayello E. Increased bacterial burden and infection: NERDS and STONES. WOUNDS UK. 2007;7(2):25-46.

21. Levine NS, Lindberg RB, Mason AD, Pruitt BA Jr. The quantitative swab culture and smear: A quick, simple method for determining the number of viable aerobic bacteria on open wounds. JTrauma. 1976;16(2):89-94.

22. Dolgov VV, Menshicov VV. Clinical Laboratory Diagnostic: National Guideline. Moscow: GEOTAR Media; 2012.

23. Paramonov B.A. Burns. Saint Petersburg: Speclit; 2000.

24. White J, Ivins N, Wilkens A, Carolan-Rees G, Harding KH. Non-contact low-frequency ultrasound therapy compared with UK standard of care for venous leg ulcers: a single-centre, asessor-blinded, randomised controlled trial. Int Wound J. 2016;13(5):833-842.

25. Gottrup F, Apelqvist J, Bjansholt T et al. EWMA document: antimicrobials and non-healing wounds-evidence, controversies and suggestions. J Wound Care. 2013;22(Supp1 5):S1-S92.

26. Percival SL, McCarty SM, Lipsky B. Biofilms and wounds: an overview of the evidence. Adv Wound Care. 201;4(7):373-381.

27. Seth AK, Geringer MR, Hong SJ, Leung KP, Galiano RD, Mustoe TA. Comparative analysis of single-species and polybacterial wound biofilms using a quantitative, in vivo, rabbit ear model. PLos One. 2012; 7(8):e42897.

28. Yao M, Hasturk H, Kantarci A et al. A pilot study evaluating non-contact low-frequency ultrasound and underlying molecular mechanism on diabetic foot ulcers. Int Wound J. 2014;11(6):586-593. 


\section{Publish your work in this journal}

Chronic Wound Care Management and Research is an international, peer reviewed, open access, online journal publishing original research, reviews, editorials, and commentaries on the causes and management of chronic wounds and the major issues related to chronic wound management. Topics also include chronic wounds as comorbidities to other conditions, patient adherence to therapy, and the economic burden of chronic wounds. The manuscript management system is completely online and includes a very quick and fair peer review system, which is all easy to use. Visit http://www.dovepress.com/testimonials.php to read real quotes from published authors.

Submit your manuscript here: https://www.dovepress.com/chronic-wound-care-management-and-research-journal 